\title{
EDUCACIÓN CÍVICA LIBERAL E MULTICULTURALISMO
}

\author{
Nicanor R. Fuentes LaÍÑo \\ I.E.S. Antón Losada Diéguez, A Estrada \\ bttp://dx.doi.org/10.15304/ag.37.2.4389
}

\section{Resumen}

La reciente producción bibliográfica liberal centrada en cuestiones educativas será el objeto de este artículo que busca presentar los debates internos de un liberalismo que elabora su proyecto de educación cívica en el contexto de sociedades democráticas caracterizadas por la multiculturalidad. Por lo tanto, intentaremos mostrar, al hilo de diversas propuestas liberales de educación cívica, ciertas discusiones relevantes que se dan dentro de la propia teoría política liberal. Estas tensiones existentes en el seno del liberalismo contemporáneo resultan especialmente instructivas cuando de lo que se trata es de poner de manifiesto los retos que tiene que afrontar un programa de educación cívica en un marco multicultural. A este respecto, la principal cuestión a dilucidar estriba en la investigación de cómo es posible encajar las demandas de reconocimiento cultural dentro de una política educativa democrático-liberal.

Palabras clave: democracia multicutural, educación cívica liberal, escuela pública.

\begin{abstract}
This paper is a survey of recent work on liberal-democratic civic education. The main goal is trying to offer an approach to the dilemmas of public schooling in pluralistic societies. Accordingly, these are some points to discuss: How can a liberal-democracy build a common civic identity among group based diversity? Which values could be shared by democratic citizens who are members of different religious, ethnical or linguistic communities? To sum up, this article wants to show the dificulties of public shools in order to educate children in shared civic virtues. Specially, in a social context in which families and churches socializate them in their particular moral values and religious beliefs.

Keywords: multicultural democracy, liberal civic education, public school.
\end{abstract}

Recibido: 29/10/2017. Aceptado: 20/12/2017. 


\section{Os conflitos educativos: familias, igrexas, escola pública}

Esta aproximación aos debates internos dun liberalismo que formula un programa de formación política da cidadanía dende a asunción de que vivimos en sociedades plurais non se reduce meramente ao ámbito teórico, senón que garda relación directa cos conflitos educativos que teñen lugar na escola pública ${ }^{1}$. Certamente, estes debates académicos entre liberais son en grande medida un fiel reflexo dos desafíos aos que se ten que enfrontar a propia institución escolar de titularidade estatal dado o carácter profundamente heteroxéneo das modernas sociedades democráticas. A apreciación da heteroxeneidade de crenzas e opinións asociada á virtude da tolerancia e á liberdade de conciencia está presente dende os seus inicios na autocomprensión liberal da Modernidade. Pero este fenómeno do pluralismo de ideas e estilos de vida acentúase nas actuais sociedades globalizadas, especialmente como consecuencia dos fluxos migratorios. Conforme á consideración netamente liberal, esta diversidade é un valor que cómpre protexer, pero que tamén supón serios retos para os réximes democráticos:

Public education in virtually every Western country is in the cross hairs of this internal conflict within liberalism. Furthermore, because populations are migrating from many differents parts of the globe, challenging previously taken-for-granted cultural assumptions, almost every country in the Western world is confronted with this issue. [McDonough and Feinberg $(2003,8)]$

A relevancia das controversias no seo da opinión pública sobre a educación que se imparte na escola estriba en que involucra elementos consubstanciais do ideario liberal e do réxime de convivencia democrático. Nos debates máis candentes, a propia consideración da Modernidade como un proceso de secularización da sociedade que cristaliza na separación de Igrexa e Estado é obxecto de discusión e incluso de revisión. Deste xeito, a lexislación estatal en materia de educación é motivo de obxección por parte das familias de crenzas relixiosas, amparándose na liberdade relixiosa e nos dereitos dos pais a elixir unha educación para os seus fillos acorde cos seus valores morais. Outras veces, as demandas de recoñecemento das comunidades relixiosas forzan aos poderes públicos a reformular o principio

1 "The central context to be examined is the institution of American public schooling, and the episodes are often conflicts between the asserted imperatives of civic education and the claims of families, churches, and other groups to be free to raise their own children in their own ways. On one side are the imperatives of civic education, on the other are a host of claims involving parental rights, the free exercise of religion, and the good of cultural and religious diversity.” Macedo $(2003,6)$. 
de igualdade civil para incorporar certas exencións a unha norma de carácter xeral. Tanto a apelación ao exercicio do dereito de obxección de conciencia como a implementación de medidas de acomodación específicas para os integrantes dunha colectividade nunca están exentas de polémica². Non resulta estraño, pois, que a escola estatal sexa obxecto de desacordos políticos e de acusadas divisións sociais que se palpan na vida pública das nosas sociedades democráticas.

The objections raised against the public schools allow us to examine critically some of the deepest divisions and most intractable conflicts that characterize the public lives in modern states. (...) Public schools controversies, today as a century and a half ago, help reveal the principal fault lines between religious communities and the secular state: the conflicts that occur here go to the heart of the liberal public settlement. [Macedo (2003, 39, 151-152)]

\section{Repensar a cidadanía liberal, repensar a educación liberal}

O renovado interese dos liberais pola educación cívica ten que ver coa toma de conciencia por parte de certos sectores do propio liberalismo da necesidade de elaborar un concepto normativo de cidadanía máis denso que a escuálida concepción legaliforme da cidadanía como mero suxeito de dereitos e deberes. Moitos teóricos liberais percátanse de que a pervivencia e a saúde da propia democracia liberal esixe manexar unha noción máis ampla de cidadanía. A diferenza dos liberais máis ortodoxos, que confían nos dispositivos de carácter institucional para asegurar un eficiente funcionamento do sistema político, os liberais de novo cuño fan fincapé en que os cidadáns deben adquirir os hábitos requeribeis para a preservación do modo de convivencia democrático. Este ensanchamento da idea de cidadán leva aparellada unha nomenclatura que inclúe entre o seu vocabulario termos tales como compromiso, participación e responsabilidade; chegando incluso a incorporar a terminoloxía republicana das virtudes cívicas.

Prácticamente en todo orden político, sea o no liberal y democrático, se necesitan algunas virtudes. Esto incluiría ciertas virtudes generales, como el coraje y el acatamiento de la ley, y también ciertas virtudes económicas, como la capacidad de retrasar la gratificación personal o adaptarse a los cambios económicos y tecnológicos. Pero también existen ciertas virtudes que son específicas de una democracia liberal,

2 "(...) do state oficials - operating on the basis of their democratic mandate- have the authority to condition a benefit such as free public schooling on the willingness of parents to have their children exposed to diversity, or does doing so violate fundamental rights or run afoul of some other principled limit on public authority?” Macedo $(2003,161)$. 
virtudes relacionadas con los principios básicos de un régimen liberal y con el papel político que los cidadanos ocupan en él.

(...) Esto demuestra, una vez más, que la educación para la ciudadanía no es simplemente cuestión de enseñar los hechos básicos sobre las instituciones gubernamentales o los principios constitucionales. Es también cuestión de inculcar hábitos, virtudes e identidades particulares. [Kymlicka $(2003,344,372)$ ]

Non é de estrañar que, ao calor desta nova visión da cidadanía, medren moi variados programas de educación cívica liberal que levan a renovar a idea de escola pública ${ }^{3}$. Efectivamente, este repensar a cidadanía dende unha perspectiva liberal capaz de apropiarse asemesmo de elementos outrora considerados exclusivos do discurso republicano, leva forzosamente a ter que reformular as bases sobre as que se asenta a socialización política. Sectores cada vez máis numerosos do liberalismo van asumindo, pouco a pouco, que as actitudes e as aptitudes da cidadanía democrática non xurden espontaneamente, senón que deben ser adquiridas polos cidadáns. Para acadar estas metas faise necesaria a concorrencia da sociedade civil e especialmente dos poderes públicos que, grazas á educación cívica, inculquen nos cidadáns o compromiso coas institucións democráticas.

En resume, co rexurdir da teoría política da cidadanía, recupérase o interese dos pensadores liberais polas cuestións educativas. Xorde así unha literatura liberal que a través dun conxunto heteroxéneo de obras aborda unha serie de temas especificamente vencellados á formación cívica.

\section{Os retos do proxecto cívico dun liberalismo sensible ás diferenzas}

O obxecto deste escrito é, pois, tratar de plasmar non tanto os postulados como as dificultades que se presentan a modo de desafíos internos á propia teoría liberal como consecuencia do intento de formular un proxecto de educación cívica sensible á diversidade ${ }^{4}$. Esta atención á diversidade comporta pensar os requisitos dun programa de educación cívica que

${ }^{3}$ Esta revisión da cidadanía liberal rica en normas e valores trasládase tamén á escola. De tal forma que a idea de escola pública propia dunha democracia liberal dará protagonismo a contidos de carácter socializador e moralizador anteriormente relegados por consideracións de índole casi exclusivamente lexislativas. Un dos obxectivos deste traballo consiste precisamente en perfilar, sen afán de profundidade, a noción de escola pública que manexan estes pensadores liberais preocupados por abordar a intersección entre educación e diversidade.

4 "How should a liberal public morality, properly understood, respond to the challenge of diversity?" Macedo $(2003,7)$. 
pretenda formar cidadáns para a convivencia democrática, tomando en consideración as demandas de recoñecemento cultural que se trasladan ao espazo escolar ${ }^{5}$.

Sendo como é o liberalismo, xa dende as súas orixes en Locke, unha doutrina dos límites do poder político, unha educación cívica liberal atenta á diversidade ten necesariamente que indagar en dous asuntos cruciais. Por unha banda, suscítase a cuestión acerca dos límites da acomodación das identidades culturais no ámbito escolar; este primeiro asunto atinxe evidentemente ás reivindicacións do multiculturalismo en relación coas políticas educativas implementadas polos gobernos. Por outra banda, está a cuestión dos límites da inculcación lexítima por parte das autoridades educativas dunha identidade compartida pola cidadanía; este último asunto ten que ver coa lexitimidade das imposicións educativas do Estado democráticoliberal.

Trataremos polo tanto de dar conta dalgúns dos dilemas e paradoxos máis recurrentes aos que se ten que enfrontar un liberalismo afín á linguaxe do recoñecemento e da identidade no intre en que se dispón a elaborar unha teoría política da educación democrática.

Para acoutar adecuadamente a exposición, presentaremos de seguido os debates que se producen como resultado do cruzamento entre liberalismo e multiculturalismo. Debates que someten a fortes tensións tres ideas-forza da doutrina liberal: a noción de autonomía persoal, a neutralidade do Estado e o papel da sociedade civil no ámbito da formación cívica.

\section{A loita polo recoñecemento e o debate en torno á autonomía individual}

As primeiras dificultades ás que se ten que enfrontar un proxecto de educación cívica liberal que trate de fomentar a formación dos mozos na igualdade e na liberdade xorden cando o seu contorno familiar ou comunitario é reticente ou abertamente contrario á promoción destes valores democráticos. Atopámonos ante o problema do artellamento da diversidade e máis a autonomía; noutras palabras, coa dificultade de encaixar a autonomía persoal dentro da integridade de grupo. ¿Como formar suxeitos autónomos en contextos culturais (ou relixiosos) opostos ao cultivo da autonomía individual?

\footnotetext{
5 "the requirements of citizenship education in liberal-democratic political theory as it has evolved in recent years, in order to take into account claims for cultural recognition through education.” McDonough and Feinberg (2003, 8).
} 
Respecto da noción de autonomía, hai que dicir que na literatura liberal relativa á educación cívica atopamos unha parcialmente renovada acepción deste termo que se ben respecta o significado xeral adquirido ao longo do corpus liberal, introduce certos matices a tomar en consideración. Así, aparece definida a autonomía como a capacidade crítica para revisar os propios valores e fins vitais, a saber, aqueles valores, normas, crenzas, saberes, prácticas e fins nos que fomos socializados durante a infancia e a adolescencia. Pero esta autonomía persoal reformulada, que conleva a posibilidade de revisar a nosa propia bagaxe cultural, toma en consideración o contexto so$\mathrm{cial}^{6}$. O tipo de educación imprescindible para que os mozos poidan desenvolver esta modalidade de autonomía pasa necesariamente pola exposición das xeracións novas a outros estilos de vida boa (na formulación liberal). En consecuencia, a educación cívica que vai na procura da autonomía ten que darlles a oportunidade de poder comparar o modo de vida familiar ou comunitario con outras maneiras de vivir. No que atinxe ao desenrolo da autonomía, o papel da educación escolar radica precisamente nesta exposición dos estudantes a outras formas de vida distintas ás dos seus proxenitores. Polo tanto, un ideario educativo liberal busca ofrecer aos escolares a posibilidade dunha comparación crítica facilitándolles a ocasión para o autoexame do seu propio estilo de vida herdado a través da educación paterna.

As inhabitants of pluralistic, tolerant societies they are confronted with a variety of different ways of life and called upon to choose. And having choosen, they yet may choose again; they may engage in critical self-examination, revise their plans and projects, and, in some ways, even alter or shape their very character. Their ends and purposes, roles, occupations, and lifestyles are not given and never fixed. Liberal politics, the rule of impersonal law and individual rights, protects the liberty to explore various ways of realizing the good life, and to exercise self-critical, self-transforming reflective capacities. [Macedo $(1991,204)]$

Para que esta avaliación poida levarse realmente a cabo é necesario poñer en contacto aos escolares coa diversidade social e cultural da sociedade e do mundo no que habitan. Unha praxis educativa encamiñada nesta dirección xera un espazo de intersección entre autonomía e pluralismo, dous dos máis importantes valores liberais. Dende esta perspectiva, liberdade individual e diversidade parecen valores que acertan a reforzarse reciprocamente. Pero

6 "strong evaluation", "situated autonomy" vs "Kantian or situationless autonomy" vid. Macedo (1991, 226 e ss). 
esta harmonía é fráxil e non sempre se acada, erixíndose moitas veces un dos valores en prioritario fronte ao outro.

Para un liberal sensible ás diferenzas que trata de elaborar un programa de educación cívica, aparece un desafío ineludible xusto no momento en que toca calibrar o alcance da autonomía individual cando esta compromete a integridade grupal, a saber, cando incentivar a autonomía dos integrantes do grupo supón unha ameaza latente ou manifesta para a súa cohesión interna. Polo tanto, a dificultade para un programa de educación cívica liberal que ao mesmo tempo trate de prestar atención á diversidade xorde cando certas formas de socialización primaria fornecedoras da cohesión comunitaria son abertamente contrarias ao valor da autonomía persoal. Nestes casos, preséntase un dilema ineludible entre optar por cultivar nos mozos as disposicións críticas necesarias para cuestionar a tradición ou tratar de inculcarlles o respecto incondicional á autoridade paterna e relixiosa.

Nesta tensión entre, por unha parte, as reivindicacións que trasladan ao ámbito escolar as familias e as comunidades culturais, relixiosas, étnicas ou lingüísticas e, por outra, as lexítimas imposicións das autoridades educativas públicas, os teóricos do liberalismo decántanse a favor dun ou doutro extremo desta dicotomía en base a favorecer a prevalecencia ou ben da autonomía dos individuos ou ben da pervivencia do grupo de socialización primaria7. Algunhas propostas de educación cívica liberal optan por conceder prioridade ao cultivo da autonomía persoal nos novos a través do coñecemento doutros estilos de vida en detrimento da pertenza grupal, argumentando que non cabe subscribir unha aceptación acrítica da diversidade. Estos liberais ${ }^{8}$ esgrimen a tese de que a diferenza non é un valor per se, e seríao moito menos no caso de ter que sacrificar a facultade de decisión persoal en aras de protexer a unidade do grupo. Os compromisos adquiridos a título individual coa comunidade cultural ou relixiosa deben ser examinados á luz dun valor superior como é o caso da autonomía individual e de lealtades moito máis relevantes como as que se derivan da pertenza á comunidade política democrática e á comunidade moral integrada polo conxunto da humanidade. Noutro polo, situaríanse aqueles liberais que

${ }^{7}$ A pesar de admitir que un Estado liberal debe facer conscientes aos escolares da existencia doutros estilos de vida para educalos na tolerancia, Galston conclúe decindo: "What it may not do is prescribe curricula or pedagogic practices that require or strongly invite students to become skeptical or critical of their own ways of life." Galston (1995, 529).

${ }^{8}$ Entre os que se inclúen Macedo, Gutmann, Callan, ou Kymlicka. 
toman como modelo o proxecto da Reforma ${ }^{9}$ para abordar as consecuencias políticas que se derivan da existencia de diferentes confesións relixiosas dentro dun mesmo corpo político. Esta corrente do liberalismo concede prioridade á diversidade sobre a autonomía, se ben dentro dos requisitos esixibles para a permanencia da propia sociedade liberal como estrutura política unitaria ${ }^{10}$.

\section{O axioma liberal da neutralidade do Estado ante as demandas dos grupos identitarios}

Neste apartado daremos conta dos dilemas que ten que resolver o Estado neutral defendido polos liberais ao ser interpelado polas demandas de recoñecemento por parte das comunidades culturalmente diferenciadas. Frecuentemente, o principio liberal de neutralidade aparece resumido na idea de que os poderes públicos non deben fomentar (nin tampouco obstaculizar) unha particular concepción de vida boa. Pero como veremos a continuación, esta acepción corresponde unicamente a unha concreta visión da neutralidade que poderíamos cualificar de ortodoxa ou tradicional ${ }^{11}$. Esta concreta concepción da neutralidade ten a súa correspondente visión da autoridade educativa liberal, imparcial e neutral no plano dos valores ${ }^{12}$. De tal xeito que a neutralidade liberal en materia educativa conlevaría a promoción do ideal pedagóxico da libre elección, permitindo que os propios escolares elixan os seus valores, evitando deste modo calquera tipo de adoutrinamento ${ }^{13}$.

Pero esta versión mainstream é seriamente cuestionada; de feito, existen varias formulacións do principio de neutralidade ${ }^{14}$. A literatura liberal

${ }^{9}$ The Reformation Project vs The Enlightenment Project, vid. Galston (1995, 525 e ss).

10 “(...) beyond the unity required for and provided by shared liberal purposes, the liberal state must allow the fullest posible scope for diversity. And the promotion of personal autonomy is not among the shared liberal purposes. Autonomy is one possible mode of existence in liberal societies - one among many others...but the devotees of autonomy must recognize the need for respectful coexistence with individuals and groups that do not give autonomy pride of place." Galston $(1995,525)$.

11 "Historically one common theme of liberal thought is that the state must not favor any comprehensive doctrines and their associated conception of the good." Rawls (1996, 190).

12 "The colorblind teacher" vs "the culturally sensitive teacher", vid. McDonough and Feinberg $(2003,6)$.

${ }^{13}$ Dende a defensa dunha educación substantiva en valores, Amy Gutmann acomete unha crítica da autoridade educativa liberal e neutral, e do seu correspondente modelo pedagóxico da clarificación de valores (values clarification), vid. Gutmann (2001, 54 e ss).

${ }^{14}$ En Rawls encontramos unha revisión crítica de certos modelos de neutralidade liberal ("procedural neutrality", "neutrality of effect or influence") e a súa propia proposta 
que propón un modelo de cidadanía sensible ás diferenzas ou multicultural acomete un labor de reformulación da tradicional e ortodoxa idea da neutralidade do Estado; tal revisión pasa por admitir que o Estado ten que xogar un papel máis activo en dous ámbitos: por unha banda, é necesaria a intervención estatal para asegurar non só a protección, senón incluso a promoción da diversidade cultural. Esta actuación lexítima do Estado xustifícase dende a óptica liberal en atención á preservación da variedade cultural que ao mesmo tempo aparece intimamente ligada ao valor liberal do pluralismo. Polo tanto, a protección e a promoción das diferenzas culturais como manifestación do pluralismo de estilos de vida ao que se acollen os individuos esixe a adopción de políticas activas por parte do Estado e non meramente unha posición neutral ante a pluralidade cultural.

Ademais, os defensores da educación cívico-democrático sosteñen que a neutralidade liberal ben entendida non pode ser valorativamente neutra debido a que a institución escolar está activamente comprometida coa formación moral dos mozos e que por este motivo fomenta determinados valores, como por exemplo a autonomía. Neste punto reaparece a tensión: por un lado, os avogados do axioma liberal da neutralidade axiolóxica do Estado observan con preocupación que por parte da escola de titularidade estatal se poidan transmitir valores, certamente encomiables como a autonomía persoal, pero sectarios e controvertidos, en tanto que non son valores universalmente compartidos, senón propios dun liberalismo (comprehensivo) que trata de inculcar nos menores unha particular visión da vida boa. Por outro lado, aqueles que opinan que a institución escolar non pode ser moralmente neutra, aseguran que esta debe educar en certos valores que rebasan con creces a mera visión política da persoa ${ }^{15}$ estritamente necesaria para a pervivencia da sociedade liberal. Estes últimos tamén admiten que as institucións e as políticas democrático-liberais teñen claros efectos sobre os estilos de vida das comunidades culturalmente diferenciadas e polo tanto, sobre as vidas dos individuos que as integran. Valores, virtudes, principios e institucións propias do Estado democrático-liberal non son neutrais en relación aos variados proxectos de vida que alberga unha sociedade plural. Consecuentemente, a política educativa liberal tampouco é neutral nas súas derivacións ${ }^{16}$; o feito de formar aos educandos en certos valores que

alternativa ("neutrality of aim") coas súas correspondentes correccións e os seus importantes matices. Vid. Rawls (1996, 191-194).

15 Tal e como a manexa por exemplo Rawls en Political Liberalism (vid. bibliografía).

16 "Non-neutral consequences", "nonneutral effects" en Macedo $(2003,12,188)$. 
redundan, por exemplo, na tolerancia e no respecto, favorece a todas luces determinados patróns de vida en detrimento doutros menos tolerantes e escasamente respectuosos coa diversidade cultural en xeral e coa relixiosa en particular.

Recapitulando: non é factible unha neutralidade perfecta ${ }^{17}$ (substantiva ou de efectos), dada a imposibilidade real de asegurar que as accións dos poderes públicos teñan consecuencias neutras sobre as concepcións morais ou relixiosas profesadas polos individuos. Ademais, soster este tipo de neutralidade valorativamente aséptica implicaría manterse equidistante tanto dos grupos que recoñecen a lexitimidade das autoridades e das políticas democráticas como daqueles outros que as rexeitan de plano. Polo tanto, non cabe acoller calquera tipo de diferenzas por parte das institucións públicas, xa que existen uns límites razoables que acoutan a diversidade de modos de vida compatibles coa democracia liberal. Os principios de xustiza que deben guiar as políticas postas en marcha polas administracións públicas, incluídas as políticas educativas, autorizan as debidas restricións e interferencias estatais en certas prácticas individuais ou colectivas contrarias ao ideal liberal da persoa e do cidadán.

Posto que non existe unha perfecta neutralidade libre de efectos, hai que admitir que as imposicións dos poderes públicos poden resultar gravosas para os estilos de vida practicados por determinados colectivos; co obxectivo de paliar estas consecuencias lesivas para a integridade de certos grupos, o liberalismo sensible ás diferenzas contempla a posibilidade de aplicar algunhas exencións que pemitan acomodar a diversidade de formas comunitarias de vida dentro da unidade do corpo político ${ }^{18}$, pero simultaneamente adopta unha actitude belixerante co encaixe daquelas comunidades cuias tradicións culturais están en aberta oposición cos principios e os valores que encarna o Estado democrático-liberal. Así, un número nada desdeñable de liberais defende un encaixe crítico, no sentido en que non cabe acomodar todo tipo de idiosincrasias, senón unicamente aquelas particularidades que sexan admisibles por resultar compatibles co modus vivendi propio dunha sociedade rexida por prácticas e institucións nas que se materializan os principios e os valores democrático-liberais. Volvemos pois sobre un plantexamento recurrente: a neutralidade liberal (ben entendida) admite

17 "Perfect fairness", ver crítica en Macedo (2003, 188-211).

${ }^{18}$ Exemptions, accomodations: "We may sometimes accommodate or exempt dissenters when their claims do not challenge core liberal values", Macedo (1995, 490). 
distintas formas de vida social coherentes cun proxecto cívico común, pero non todas ${ }^{19}$.

\section{A polémica construción dunha identidade cívica común en contextos de diversidade}

Os teóricos da educación cívico-liberal non teñen reparos á hora de recoñecer que a cidadanía, en tanto que realidade de natureza eminentemente política, é un produto, un algo creado ou construído pola acción conxunta da sociedade civil e das institucións estatais ${ }^{20}$. Este feito crucial plantexa certas preguntas ineludibles para calquera modelo de teoría política da educación democrática (sexa ou non liberal): ¿como se forma aos cidadáns dunha sociedade democrática?, ¿que tipo de educación é precisa? ${ }^{21}$ Pero estas cuestións xa de por si complexas aínda se complican máis se pensamos a cidadanía democrática dende a pluralidade: ¿como se constrúe a identidade cívica en contextos de diversidade?22

Os teóricos da educación cívica liberal admiten sen complexos que os poderes públicos teñen que asumir a tarefa de promoción duns valores comúns e dunha identidade cívica compartida que se superpoña ás identidades particulares e que actúe como elemento de cohesión interna da comunidade política. Este asunto non está exento de polémica na propia teoría liberal ao suscitarse o problema da construción e a implantación dunha identidade nacional común nun marco de diversidade crecente. Reparemos no problema que supón tratar de facer compatible a neutralidade do Estado ante os distintos estilos de vida que adoptan os individuos adscritos ás máis diversas comunidades co simultáneo e imprescindible fomento dunha identidade nacional (que sempre vai estar de xeito inevitable) culturalmente connotada. Esta complicada relación do Estado liberal (e neutral) coa multiculturalidade resulta se cabe aínda máis complexa se lle engadimos as peticións do multiculturalismo. Traducido noutros termos, atopámonos ante

19 "Prudential accommodationism" vs "indiscriminate aspirations to fairness or neutrality", en Macedo (2003, 196 e ss).

20 "There is no reason to think that the dispositions that characterize good liberal citizens come about naturally: good citizens are not simple born that way, they must be educated by schools and a variety of other social and political institutions”, Macedo (2003, 16).

21 "What constitutes an adequate education for liberal democratic citizenship?", Gutmann (1995, 560).

22 "How can we justify basic political principles in a society in which people disagree about their religious convictions and philosophical ideals", Macedo $(2003,166)$. 
a omnipresente tensión entre a unidade e a diversidade tantas veces abordada na filosofía política; particularmente, na literatura liberal que presenta un programa de educación cívica a tensión unidade/diversidade tradúcese nun potencial conflito entre, dunha banda, o común, o público, a saber, principios, valores, virtudes, leis e procedementos propios das institucións e da cidadanía que se derivan da pertenza dos individuos a unha comunidade política democrática. Mentres que pola outra banda atopamos o diverso, o particular (catalogado tamén como o privado), isto é, crenzas, normas, tradicións, saberes e patróns de conduta adquiridos a través das formas de socialización familiar ou comunitaria e que dan conta da pertenza dos individuos a determinadas comunidades definidas en función dunha concreta marca identitaria ${ }^{23}$.

Esta tensión entre a unidade e a diversidade xera constantes debates internos na propia teoría política liberal. A modo de anticipo: se o diverso ven marcado pola pertenza plural dos individuos a comunidades de natureza relixiosa, cultural, étnica ou lingüística, etc., suscítase de xeito inmediato a pregunta acerca do común: ¿que debe ser compartido por todos os individuos en tanto que membros dunha sociedade democrática e plural? Ademais, se ben os liberais proclaman abertamente que o conflito de valores é unha realidade inherente a unha sociedade plural, permanece a dúbida sobre qué valores deben primar en caso de confrontación, se os comúns á sociedade democrática ou os particulares e propios das comunidades diferenciadas. Entón: ¿¿deben prevalecer os valores públicos da ética cívica por riba dos valores circunscritos ao ámbito das familias e das comunidades étnico-relixiosas? No ámbito da educación cívica liberal, estes dilemas dan conta da complicada concordancia entre a protección da diversidade que ven esixida pola defensa do pluralismo e a promoción dunha identidade cívica compartida que se fai necesaria para a preservación do corpo político democrático ${ }^{24}$. Ámbolos dous polos da tensión delimitan tanto o marco teórico

23 "Multicultural societies throw up problems that have no parallel in history. They need to find ways of reconciling the legitimate demands of unity and diversity, achieving political unity without cultural uniformity, being inclusive without cultural uniformity, being inclusive without being assimilationist, cultivating among their citizens a common sense of belonging while respecting their legitimate cultural differences, and cherishing plural cultural identities without weakening the shared and precious identity of shared citizenship", Parekh, B., Rethinking Multiculturalism: Cultural Diversity and Political Theory (Macmillan, London, 2000) apud McLaughlin. T. H., "The Burdens and Dilemmas of Common Schooling", en McDonough and Feinberg $(2003,121)$.

24 "If our aim is to promote a political order that is characterized by a healthy measure of liberal democratic virtue, what are the implications for diversity? What is the relation 
xeral como o concreto campo de actuación das políticas educativas implementadas polos Estados democrático-liberais que intentan compaxinar a formación cívica coa atención á diversidade. Non atoparemos unha resposta unánime para os desafíos que ten que encarar un proxecto nitidamente liberal de educación cívica en contextos educativos nos que se fan patentes unhas específicas demandas de recoñecemento; sen embargo, poderíamos englobar grosso modo a variedade de respostas liberais baixo dúas grandes tendencias que exemplifican axeitadamente os debates internos que tratamos de recoller nesta exposición.

Como xa sinalamos anteriormente, para moitos liberais resulta extremadamente controvertida a promoción dos valores cívicos vía institución escolar de titularidade estatal en contextos de diversidade cultural e relixiosa. $\mathrm{O}$ argumento esgrimido fai fincapé en que a necesaria neutralidade do Estado ven esixida como prevención ante o perigo de que a escola pública adoutrine nunha determinada visión comprehensiva da natureza humana; concretamente, a neutralidade de valores do Estado liberal e da súa institución educativa require indefectiblemente que os contidos cívicos nos que se instrúa aos escolares sexan estritamente políticos, isto é, acordes coa visión político-institucional do liberalismo, e polo tanto, carentes de específicas connotacións filosóficas ou morais. En todo momento hai que evitar inculcar os valores dunha particular visión comprehensiva da natureza humana, xa que no seo das sociedades democráticas existe unha pluralidade de concepcións igualmente razonabeis acerca do que é a boa vida acorde con certos valores e fins. En resume, a escola pública debe absterse de interferir nos procesos de socialización primaria das familias impoñendo ou favorecendo unha determinada visión da boa vida humana. Coherentes con este plantexamento resultan as propostas máis ortodoxas de educación cívica liberal que recelan das institucións públicas (incluída a escola de titularidade estatal) sempre propensas a invadir o ámbito da libre decisión dos axentes que actúan no espazo plural da sociedade civil. Conforme a este modelo, a instrución cívica consistiría na ensinanza dun conxunto de contidos que deberían integrar a bagaxe requerida para o correcto funcionamento da democracia liberal. Estamos a falar, por exemplo, do coñecemento dos órganos fundamentais do Estado, da Constitución e dos dereitos e deberes dos cidadáns recollidos na Carta Magna, da Declaración Universal dos Dereitos Humanos, así como do valor de respectar a lei. Un tipo de instrución necesario

between a liberal constitutional order, understood as a normative or moral structure, and the other normative structures that exist within a polity?" Macedo $(2003,13)$. 
para o exercicio da cidadanía liberal que debe absterse da transmisión de valores e que concede ás familias a potestade de fixar os límites das políticas educativas implementadas polos poderes públicos ${ }^{25}$.

Este programa de educación cívica liberal recibe o nome de minimalismo cívico $^{26}$, é tildado precisamente de insuficiente por operar cunha concepción fortemente legaliforme da cidadanía e por descoidar unha formación moral acorde cos valores da cidadanía democrática. Polo tanto, dentro da educación liberal existe outra tendencia que aposta decididamente por unha concepción máis densa tanto da cidadanía como da educación cívica; decimos máis densa para referirnos a unha visión politicamente connotada da cidadanía que non concibe aos cidadáns meramente baixo un aspecto legal (como suxeitos de dereitos e deberes), senón que pensa aos actores do espazo público dende as virtudes cívicas necesarias para a deliberación democrática e a participación política. Ademais, búscase artellar esta noción densa da cidadanía cun ideario de educación cívica que adquire o estatus de moral pública. Así, estas correntes do liberalismo pasan a cuestionar con moderación ou a relativizar en certa medida o axioma liberal da neutralidade do Estado. A conclusión á que se chega é que a escola pública non pode nin debe ser neutral, posto que necesariamente debe transmitir e transmite os valores e os principios propios do civismo democrático. Así pois, o currículum dunha eficaz formación da cidadanía que sirva de sostén á democracia liberal rebasa con creces os contidos meramente institucionais, constitucionais e legais postulados por unha concepción política liberal ortodoxa, propia do minimalismo cívico ${ }^{27}$. En definitiva, este ambicioso proxecto de educación cívica liberal non inclúe unicamente os coñecementos (aptitudes), senón tamén as actitudes (virtudes) imprescindibles para o efectivo desempeño da cidadanía democrática e pode, en consecuencia, ser adecuadamente considerado como unha ética cívica.

A diferenza do minimalismo cívico, que atribúe ás familias un papel certamente preponderante ate o extremo de facer prevalecer a elección paterna

${ }^{25}$ A modo de ilustración pode servir a obxección de grupos de pais de confesión católica á disciplina de Educación para a Cidadanía. A posible réplica dos liberal-demócratas como Amy Gutmann é contundente: "The religious freedom of adults... does not entail a right to deny their children an education adequate for liberal democratic citizenship." Gutmann (1995, 568). Véxase tamén Macedo (2003, 201-202).

${ }^{26}$ Para unha sucinta descripción do minimalismo cívico, vid. McLaughlin, T. H. "The Burdens and Dilemmas of Common Schooling", en McDonough and Feinberg $(2003,130)$.

${ }^{27}$ De tal modo que se trataría de trasladar á aula determinados debates de interese para a opinión pública como, por exemplo, os relativos ao aborto, a eutanasia, o matrimonio homosexual, a transexualidade ou os ventres de aluguer. 
á hora de decidir qué clase de formación deben recibir os escolares, este outro modelo de educación liberal-democrático outorga plena lexitimidade ás imposicións das autoridades públicas en materia educativa ${ }^{28}$. Asemade, a lexislación educativa está investida dunha especial relevancia posto que as políticas educativas desempeñan un papel determinante en tanto que son a cristalización das decisións colectivas que o conxunto da sociedade adoptou para a perpetuación do réxime democrático de convivencia. Avógase por unha autoridade educativa compartida ${ }^{29}$ entre as partes que teñen un lexítimo interese na educación dos mozos; os pais e as nais, en tanto que os educandos son fillos e membros da familia, e as autoridades educativas democráticas (e a través delas o conxunto da cidadanía), en tanto que son membros do Estado e futuros cidadáns con plenos dereitos ${ }^{30}$.

\section{A controversia sobre o papel dunha renovada sociedade civil na formación cívica}

Un interrogante recurrente nos debates internos entre os teóricos da educación cívica de corte liberal afecta directamente a un dos buques insignia do liberalismo, estamos a referirnos á noción de sociedade civil. A comprensión da sociedade civil como unha instancia que vixía o poder, como unha especie de contrapeso á acción do goberno e do mercado, é un dos rasgos recoñecibles da definición propiamente liberal do termo. Tamén forma parte desta autocomprensión liberal de sociedade civil o feito de que sexa entendida como un conxunto de institucións asociativas que se encontran entre o individuo e o Estado ${ }^{31}$.

O liberalismo contemporáneo, e particularmente o liberalismo sensible ás diferenzas e a teoría política da educación cívico-liberal, contribuíron

${ }_{28}$ Ámbolos dous modelos de educación cívica teñen a súa correspondencia no "Estado das familias" e no "Estado democrático da educación" respectivamente, vid. Gutmann (2001, 48-53, 62-68).

29 "We should prize and preserve the tension between the shared civic values represented by public schools and the particular moral and religious values of families, churches, and other moral communities. No one source of authority should dominate the educational landscape. Further, this division of educational authority is part of the larger mix of political institutions in a extended republic that fosters cross-cutting memberships and complex identities." Macedo (2003, 250-251).

30 "The last thing we want is any one source of authority dominating education." Macedo (2003, 245).

31 “(...) those associations and communities between the individual and the state" Galston (1995, 531). 
decisivamente á renovación da noción e do estatus da sociedade civil; de tal xeito que as variadas aportacións teóricas ensanchan este topos do liberalismo partindo da necesidade de elaborar un novo concepto normativo de cidadanía e consecuentemente de propoñer un concepto renovado de sociedade civil. Esta revisión integra no seu significado a idea dun tecido de asociacións voluntarias e involuntarias que compoñen a sociedade liberal, pero xa non concibida exclusivamente como esferas económica (empresa) e doméstica (familia), tradicionalmente conceptualizadas como o espazo privado oposto ao público-político-institucional. O concepto amplíase para recoller explicitamente no seu significado ás comunidades diferenciadas da sociedade. O característico pluralismo da sociedade civil liberal, recoñecible polas distintas formas de pensar e de vivir resultado das eleccións persoais dos individuos, comprende tamén a diversidade de estilos de vida comunitaria que adoptan os diversos grupos culturais, relixiosos, étnicos, lingüísticos, etc. Sendo así que poderiamos falar dun pluralismo das comunidades que se solapa co tradicional pluralismo dos individuos (de Stuart Mill, por exemplo).

Á luz destas precisións semánticas, cabe concretar os interrogantes aos que faciamos referencia máis arriba: ¿que específico papel ten e que estatus posúe unha sociedade civil pensada en termos de pluralidade en relación coa promoción da cidadanía?, ¿'son suficientes asociacións voluntarias e involuntarias para levar a cabo a formación política dos cidadáns do presente e do porvir?, ¿faise de todas mameiras necesaria a concurrencia dos poderes públicos para educar na cidadanía?, ¿correspóndelle á escola pública un rol protagonista, complementario ou subsidiario respecto das entidades da sociedade civil? As preguntas plantexadas deixan translucir a recoñecida tensión netamente liberal entre o espazo delimitado pola sociedade civil e o ámbito de intervención do Estado, pero nesta ocasión trasladada á teoría política da educación democrática como probable conflito entre as demandas das comunidades e as imposicións das autoridades educativas ${ }^{32}$.

Dixemos antes que a redefinición da sociedade civil lévase a cabo dende a toma en consideración, por unha banda, do pluralismo de grupos identitarios, e por outra, do papel que debe xogar na formación da cidadanía democrático-liberal.

32 "the focus is on the question of the aim of education in societies which want to advance a liberal-democratic agenda, and how those aims might need to be constrained within the context of religious or cultural groups that have a different agenda." McDonough and Feinberg (2003, 2-3). 
Visualizada como culturalmente plural e diversa, a sociedade civil transfórmase nun ámbito (evidentemente non estatal, pero tampouco estritamente privado) de interacción e diálogo entre as minorías xa asentadas e os inmigrantes recentemente chegados coa sociedade maioritaria. Sen abandoar a xa habitual nomenclatura das asociacións, bótase man dun novo vocabulario que fala de diferentes esferas autónomas, de espazos cívicos, de redes de accións comúns, de civilidade, solidariedade e de fraternidade.

O papel protagonista de contrapeso e de vixianza do poder político que noutro tempo asumía a sociedade civil vese reemprazado por unha relación de reciprocidade e de colaboración. A pluralidade de esferas autónomas e de comunidades diferenciadas que posúen as súas propias ideas do ben e os seus intereses específicos require dunha especial protección por parte dos poderes públicos para lograr a efectiva promoción da solidariedade no seo da sociedade. O lexítimo obxectivo da integración das minorías pasa pola adopción de medidas de apoio á diversidade étnica e cultural que, lonxe de alentar a desafección e a fragmentación — arguméntase- aseguran unha máis eficaz cohesión do corpo político. Medidas que pasan polo respecto ás especificidades dos grupos diferenciados en pé de igualdade e que non outorguen vantaxes ou tratos de favor a uns grupos fronte a outros que deriven en desigualdades patentes; actuacións que protexan as heteroxéneas esferas autónomas da sociedade fronte ás acometidas dos poderes económicos e os seus perversos efectos homoxeneizadores. Medidas de atención á diversidade que tamén deben ter o seu reflexo nas tarefas educativas dun xenuíno Estado plural (ou post-nacional).

A propósito do calado destas medidas, xa se manifestou noutro momento que no liberalismo sensible ás diferenzas era claramente perceptible unha acentuada tensión entre salvagardar a cohesión do grupo identitario ou a do conxunto do corpo político. Moitas veces, considérase que en caso de conflito entre as autoridades educativas e as familias, debe ter preferencia a educación paterna: os pais teñen dereito a que aos seus fillos non se lles ensinen valores nin se lles impartan contidos que contraveñan o corpus de tradicións do grupo de socialización primaria. Outros liberais estipulan que a única contrapartida esixible por parte dos poderes públicos ás familias estriba en que estas acepten que aos seus descendentes se lles ensinen as crenzas, valores e patróns de conduta doutras comunidades culturais ou relixiosas da sociedade. A intención última desta proposta sería poñer a salvo o valor liberal de autonomía, favorecendo a través do coñecemento doutros mundos culturais e relixiosos a propia elección do modelo de vida boa. A xuízo dos liberais máis seriamente comprometidos coa educación 
democrática, estas recomendacións nin garanten o desenvolvemento da autonomía persoal nin tampouco aseguran unha adecuada formación cívica. A insuficiencia deste plantexamento excesivamente centrado na reprodución dos grupos identitarios conduce a estes sectores do liberalismo a reclamar un papel civicamente máis activo para o conxunto de entidades que constitúen a sociedade civil. Así, a sociedade civil cobra un novo valor en tanto que contribúe á formación moral e política, e son numerosos os proxectos de educación liberal que enfatizan a importancia do heteroxéneo entramado asociativo da sociedade civil como unha xenuína escola para a cidadanía $^{33}$. A propia dinámica institucional da política liberal que require da intervención dos cidadáns nos procesos electorais, por exemplo, serve aos efectos da aprendizaxe das virtudes cívicas, pero a participación activa dos individuos no asociacionismo tamén lles permite adestrarse para a adquisición das capacidades necesarias para o eficiente desempeño da cidadanía democrática. Polo tanto, todo o tecido asociativo da sociedade liberal, aínda sen formar parte das institucións políticas, ten un papel nada desdeñable en relación coa política democrática ao promover diversas formas de participación social e de compromiso cívico ${ }^{34}$. Os liberais comprometidos coa educación cívica non se cansan de repetir que existe unha forte conexión entre unha sociedade civil activa e fortalecida e unha cidadanía participativa, responsable e solidaria.

We should also remember that liberal citizens will not learn justice only, or even mainly, from political participation as it is usually conceived of (voting, discussing candidates and political issues, campaigning, and so forth). From early on and throughout their lives, liberal citizens learn and apply public norms in their interactions with others. Children learn respect for rules and fair play from their parents and from childhood games. They criticize, discuss, listen to others, and take votes, they follow, debate, change, and help enforce rules, at home, in school, at work, in games, and with their friends. They gradually learn to restrain their impulses, to respecto others as equals, and to direct and apply their energies with diligence. They learn to make judgments for themselves and hopefully adquire a measure of individuality and autonomy. They learn something about due process, and fairness, and respect for those who are different; they develop judicial, legislative, and executive virtues. All for this takes place without political control, though it is all importantly influenced by our political practices. It would be wrong, therefore, to view participation in campaigns and elections as the sole or even primary font of public virtue: private life goes a long way in helping to prepare us for our public duties. [Macedo (1991, 273-274)]

${ }^{33}$ Dunne, J., "Between State and Civil Society: European Contexts for Education", en McDonough and Feinberg $(2003,107)$ : "civil society is a kind of training ground for citizenship".

${ }^{34}$ Vid. Macedo $(2003,39)$. 
Queda por dilucidar ate qué punto se poden alcanzar estes obxectivos sen a concorrencia dos poderes públicos, máis concretamente, sen a presenza destacada da escola de titularidade estatal. Así, os liberais que apostan decididamente por un modelo de democracia participativa e de cidadanía activa relativizan por diversos motivos os presumibles éxitos das entidades da sociedade civil de cara á aprendizaxe das virtudes cívicas porque transformar estas agrupacións e colectivos nunha especie de academias de cidadanía supón cargalas co peso de obrigacións moi esixentes que exceden con moito a súa función na sociedade ${ }^{35}$; arguméntase por exemplo que o obxectivo específico das familias ou das congregacións relixiosas nada ten que ver coa adquisición de capacidades políticas; hai que admitir que, en ocasións, algunhas entidades da sociedade civil promoven abertamente formas de pensar e de actuar (como a intolerancia e o machismo) que conculcan os valores democráticos ${ }^{36}$. Pero incluso recoñecendo que a escola pública non fose o único foro de formación cívica e que houbese tamén outras institucións sociais que puidesen axudar aos individuos a adquiriren as competencias necesarias para chegar a ser bos cidadáns, a escola seguiría sendo indispensable por ser o principal instrumento do que se dota unha sociedade democrática para a súa perpetuación ${ }^{37}$. Aínda admitindo a capacidade das diversas asociacións (voluntarias, e incluso non voluntarias) da sociedade civil para instruír nas aptitudes e as actitudes cívicas, sen a directa e decidida intervención das autoridades educativas públicas é absolutamente inviable unha eficaz formación cívica dos cidadáns do presente e do futuro, especialmente en contexto de diversidade ${ }^{38}$. En resumidas contas, estas son razóns de peso a favor de que a escola pública asuma a instrución política dos futuros cidadáns: non hai garantía algunha de que os mozos e as mozas aprendan os valores democráticos fóra da institución escolar ${ }^{39}$.

${ }^{35}$ Vid. Kymlicka and Norman $(1994,19)$.

${ }^{36}$ Vid. Ibid e Kymlicka (2003, 353-354).

37 "Conscious social reproduction" (reprodución social consciente), en Gutmann (2001).

38 "American public schools have been, in many ways, where the tension between diversity and the felt need to promote shared values, has played out most dramatically. This institution has, from its inception, been the principal direct public instrument for creating a shared political culture amid religious, racial, ethnic, and class diversity", Macedo (2003, 39).

39 “(...) no podemos confiar en el mercado, en la familia o en las asociaciones de la sociedad civil en lo que a la enseñanza de la virtud cívica se refiere. Las personas no aprenderán automáticamente a implicarse en el discurso público, o a cuestionar la autoridad en ninguna de estas esferas, puesto que, con frecuencia, estas esferas se mantienen unidas por el discurso privado y el respeto a la autoridad. Esto sugiere que las escuelas deben enseñar a los niños cómo implicarse en el tipo de razonamiento crítico y de perspectiva moral que define la moderación pública... la promoción de este tipo de virtudes era una de las justificaciones fundamentales de la educación obligatoria”, Kymlicka (2003, 355). 


\section{Conclusións: Educar na cidadanía multicultural}

A reformulación do concepto normativo de cidadanía a cargo das heteroxéneas e heterodoxas correntes do liberalismo de novo cuño leva aparellada a toma en consideración do compromiso cívico ${ }^{40}$ como seña de identidade dun renovado suxeito político liberal. Pero para materializar este propósito faise necesaria a posesión de certas virtudes cívicas para que o individuo liberal poida tomar consciencia de que é partícipe dun proxecto colectivo. Hai que adoptar unha visión de conxunto ${ }^{41}$ que rebase os nosos intereses particulares para atender ao ben común pero, ¿como se adquire esta perspectiva dun nós?, ¿como se xera a preocupación por un destino compartido? Responder a estas e outras cuestións semellantes conduce aos liberais a indagar na xénese da cidadanía e a preocuparse pola paideia política acorde coa democracia. Asemade, ante o feito social do pluralismo ${ }^{42}$, hai que velar tamén para que ese proxecto cívico democrático-liberal sexa quen de albergar a diversidade social. Ábrense novos interrogantes: ¿como cultivar o compromiso cívico no seo da sociedade sen recurrir aos lazos de empatía propios das afinidades étnicas, relixiosas, culturais ou lingüísticas?, ¿como formar cidadáns evitando a impronta dunha identidade nacional uniforme sen menoscabo da solidariedade cidadá?

A faciana menos afable da historia do moderno Estado-nación mostra na súa amarga experiencia que o elevado prezo a pagar pola construción dunha identidade nacional baseada na cultura dominante e nas tradicións dos grupos hexemónicos é a consecuente exclusión dos parias (cando non, o seu exterminio). Ademais, está o paradoxo de inculcar unha identidade nacional nun momento histórico en que o propio Estado nacional entra en crise baixo a presión da globalización.

A nomenclatura cidadanía diferenciada ou cidadanía multicultural acuñada polo liberalismo afín ás demandas de recoñecemento dos colectivos oprimidos e das minorías pretende ser a resposta ao reto de xerar unha cidadanía en condicións de pluralidade. Malia todo, hai que admitir que en ocasións esta nomenclatura convértese nun auténtico oxímoron cada vez

40 “Active civic engagement”, Dunne, J., en McDonough and Feinberg (2003, 101).

41 “A 'we' perspective", idem.

42 "How it is possible for there to exist over time a just and stable society of free and equal citizens who still remain profoundly divided by reasonable religious, philosophical, and moral doctrines?” Rawls $(1996,47) ;$ “(...) the permanent fact of pluralism: reasonable people disagree not only about preferences and interests, but widely and deeply about moral, philosophical, religious, and other views.” Macedo (1991, 47). 
que se coloca o acento exclusiva ou preferentemente no segundo termo da expresión. Para certas variantes dun liberalismo de carácter comunitarista que concede todo o protagonismo á preservación das entidades colectivas, o individuo é ante todo un membro dunha realidade social xa dada previamente. Deste xeito, entra en escena o grupo identitario en tanto que suxeito cuasi ou netamente prepolítico inmerso nunha sociedade civil constituída a modo de heteroxéneo conglomerado de comunidades compactas e opacas. Paralelamente, neste liberalismo comunitarista, o excesivo celo posto na protección dunha prístina identidade de grupo vai acompañado dun certo desinterese pola implantación dunha identidade cívica compartida. Chegados a este punto, fanse dificilmente concebibles tanto a educación cívica como a propia cidadanía.

Para moitos liberais, vencer estas e outras dificultades no plano da teoría pero tamén na práctica social pasa por atopar o encaixe da diversidade na unidade, noutras palabras, por acomodar a particular pertenza cultural no marco xeral da cidadanía. Unha vez que se descarta a posible constitución da cidadanía vía exclusión ou asimilación, preténdese a promoción dunha identidade cívica que acolla o pluralismo existente na sociedade. A fórmula proposta trata de conxugar a adhesión a unha comunidade cultural, étnica, relixiosa ou lingüística coa instrución para a participación política democrática. Como sosteñen os seus defensores, estaríamos a falar dunha educación cívica compatible con todas aquelas tradicións e patróns de conduta culturalmente pautados que son respectuosos cos principios e os valores democrático-liberais ${ }^{43}$. En definitiva, esta é a proposta, non exenta de contradicións e de aporías, dun programa de formación cívica adecuado a unha democracia inserta nun marco de crecente pluralidade. Queda constancia dos desafíos, tanto no plano teórico como no práctico, deste ideario de educación democrática, liberal e multicultural ${ }^{44}$.

43 Pensadoras como Melissa S. Williams, maniféstanse escépticas con relación ao éxito de semellantes propósitos: "I am less confident than these theorist [Macedo, Callan, Feinberg] that an educational project of inculcating citizen identity is easy to reconcile with the egalitarian treatment of citizens from cultural and religious minorities", "Citizenship as Identity, Citizenship as Shared Fate, and the Functions of Multicultural Education", en McDonough and Feinberg (2003, 218).

44 "Democracies today face persistent, profound, and pervasive diversity within their citizenry, and their diversity seems to be ever increasing. How can such a state survive without common substantive purposes? And how can such common purposes be pursued (and transmitted in civic education) without injustice to those whose way of life differs markedly from the norm?" Becker and Kymlicka (1995, 465-466). 


\section{Bibliografía}

Becker, Larry and Kymlicka, Will (1995), "Symposium on Citizenship, Democracy, and Education. Introduction", Ethics, Volume 105, April 1995, Number 3. The University of Chicago Press, Chicago, 1995, pp. 465-467.

Galston, William A. (1995), “Two Concepts of Liberalism”, Ethics, Volume 105, April 1995, Number 3. The University of Chicago Press, Chicago, 1995, pp. 516-534.

https://doi.org/10.1086/293725

Gutmann, Amy (1995), "Civic Education and Social Diversity", Ethics, Volume 105, April 1995, Number 3. The University of Chicago Press, Chicago, 1995, pp. 557-579.

https://doi.org/10.1086/293727

Gutmann, Amy (2001), La educación democrática. Una teoría política de la educación, Paidós, Barcelona, 2001.

Kymlicka, Will and Norman, Wayne (1994), "Return of the Citizen: A Survey of Recent Work on Citizenship Theory", Ethics, Volume 104, January 1994, The University of Chicago Press, Chicago, 1994. Versión en español: Cuadernos del CLAEH, número 75, Montevideo, 1996, pp. 81-112.

https://doi.org/10.1086/293605

Kymlicka, Will (2003), La política vernácula. Nacionalismo, multiculturalismo y ciudadanía, Paidós, Barcelona, 2003.

Macedo, Stephen (1991), Liberal Virtues. Citizenship, Virtue, and Community in Liberal Constitutionalism, Clarendon Press, Oxford, 1991.

Macedo, Stephen (1995), "Liberal Civic Education and Religious Fundamentalism: The Case of God v. John Rawls?", Ethics, Volume 105, April 1995, Number 3, The University of Chicago Press, Chicago, 1995, pp. 468-496.

https://doi.org/10.1086/293723

Macedo, Stephen (2003), Diversity and Distrust. Civic Education in a Multicultural Democracy, Harvard University Press, Cambridge, Massachusetts, 2003.

Mcdonough, Kevin and Feinberg, Walter (eds.) (2003), Citizenship and Education in Liberal-Democratic Societies. Teaching for Cosmopolitan Values and Collective Identities, Oxford University Press, New York, 2003. https://doi.org/10.1093/0199253668.001.0001

Rawls, John (1996), Political Liberalism, Columbia University Press, New York, 1996. 